\title{
Identification and Evaluation of Factors Affecting Nectar Volume and Concentrations of Croton Macrostachyus Hochst.ex Delile
}

Kasim Roba Jilo ( $\square$ kasimroba7@gmail.com )

Ethiopian Institute of Agricultural Research

Getachew Sime

Hawassa University College of Natural and Computational Science

\section{Research}

Keywords: Croton macrostachyus, environmental factors, plants age, nectar concentration, nectar volume

Posted Date: October 29th, 2021

DOl: https://doi.org/10.21203/rs.3.rs-952506/v1

License: (c) (1) This work is licensed under a Creative Commons Attribution 4.0 International License.

Read Full License 


\section{Abstract}

\section{Background:}

Secretion of nectar is highly influenced by many factors and the objective of the study was also to evaluate factors affecting concentrations of nectar of Croton macrostachyus Hochst.ex Delile. Age of plants highly affect nectar concentration and volume. Honey quality and its medicinal values depends on plants species variety and their sucrose concentration quality and quantity which is governed by many biotic and abiotic factors as well micro climate of the area. Wholesale of nectar and concentration of tend to show more differences in time of day for species study undertaken.

Results: As results publicized that nectar concentration and volume of youngest age was not more affected by temperature and relative humidity like that of medium and oldest ages. Temperature and age have significant effect on volume $(p=0.0001)$ and their interactions is also significant $(p=0.01145)$. Temperature has significant effects on nectar concentration $(p=0.000)$. Interaction of relative humidity, time, and layers has significant effects on nectar concentration $(p=0.0024012)$. The oldest plants had the highest concentration of $10.1 \mathrm{w} / \mathrm{w}$ mornings and afternoon $36.5 \mathrm{w} / \mathrm{w}$ at 4:00 PM for whereas medium plants had nectar concentration of $5.7 \mathrm{w} / \mathrm{w}$ morning and afternoon $16.7 \mathrm{w} / \mathrm{w}$ and the smaller or younger plants had nectar concentration of $2.7 \mathrm{w} / \mathrm{w}$ mornings and afternoon $9.1 \mathrm{w} / \mathrm{w}$ and this shows age significantly affect nectar concentration and volume.

\section{Conclusions:}

Concentration and volume were affected by many biotic and abiotic factors. I conclude imminent fever intensification could harm nectar production since for croton also no nectar could be collected at $30 \mathrm{CZ}$ and no nectar recreation was observed after this peak temperature this indicates environmental change can increase the temperature which will have negative influences on honey production in the future unless we combat against climate change which will affect honey production and productivity for the country and we will lose honey and its medicinal values also.

\section{Introduction}

C. macrostachyus Hochst. ex Delile, known as broad-leaved called croton in English and is named by various vernacular names in the different areas of Ethiopia (Meresa et al.,2019). C. macrostachyus Hochst. ex Delile is a species of the genus Croton. Euphorbiaceae family, commonly known as the spurge family (Obey et al., 2018). Croton macrostachyus occurs as a pioneer species commonly on degraded mountain slopes, on disturbed areas, in borders of cultivated fields, on waste ground, along with river habitats at altitudes between 1,100 and 2,500 m. a. s. I (Alemayehu, 2018). The response of nectar secretion to external environmental and variation in nectar traits associated with intrinsic plant characteristics (Lu et al., 2015). Nectar secretion is strongly influenced by plant age (Cawoy, 2008). Plants' ability to sense their environment and respond to it is critical for their survival (Veits et al., 2018). 
The species of bee, colony within species, a month of the year, and the time of day when the nectar is collected all has a significant effect on the sugar concentration of collected nectar(Robert, 2007). Watery exudation from plants accumulates when atmospheric humidity is high and evaporation thereby is retarded this can easily be demonstrated in connection with bleeding from several tissues (RodríguezPeña et al., 2016). The east African highland Musa cultivars having the highest nectar volume have the lowest sugar concentration, while the dessert types with the least nectar volumes have the highest sugar content (Rutikanga et al.,2016). Decreased soil moisture significantly reduced the leaf relative water content (Zhang et al.,2004). It is a general assumption amongst plant physiologists and Ecologists that stomata have evolved to provide a Controlling water loss from plants while allowing photosynthesis (Jones, 2015). Daylight time has significant effects on nectar volume and concentrations of Callistemon citrinus. L (Kasim, 2019).

Volume and concentration tend to show more differences in time of day (Edge, 2010). The other revealed that there was great variability in the nectar production and it is evident that higher nectar production occurred at high humidity and low temperature (Adjaloo, 2015). Differences in microclimate can also lead to the variation observed between populations at different habitats (Farkas, 2012). The accumulation of sugar in and near the flower under the influence of low temperatures and increased permeability of the plasma membrane under the influence of high temperature (Stoner et al., 2016). It was compared that the changes in nectar secretion under temperatures expected by the end of the century and estimated the effect of climate warming on nectar secretion of plants flowering in different seasons and of very high temperatures has negative effects in all species(Takkis et al., 2018).

When humidity increases, the secretion of water, but not that of sugar, from nectaries is increased and excessive water supply lessens the sugar surplus in the parts of the flower and nectar is more dilute when humidity is high (Kasim,2019).

Watery exudation from plants accumulates when atmospheric humidity is high and evaporation thereby is retarded this can easily be demonstrated in connection with bleeding from several tissues (Stoner et al., 2016). Nectar is more dilute when humidity is high, and honey that is stored at such times is likely to be high in water content(Stoner et al.,2016).

\section{Materials And Methods}

Study area description

Hawassa is a city in Ethiopia, in the Valley. It has latitude and longitude of $7^{\circ} 3^{\prime} \mathrm{N} 38^{\circ} 28^{\prime} \mathrm{E} 7^{\circ} 3^{\prime} \mathrm{N} 38^{\circ} 28^{\prime} \mathrm{E}$ and an elevation of 1708 meters above sea level(www.hu.edu.et Background of Hawassa University October 2, 2013.

Experimental design and sample size of the experiment 
Maximum variation purposive sampling techniques were used to select trees based on their age. Each plant was categorized into three layers (layer one is the bottom layer, layer two is medium and layer three is the top layer for oldest, medium, and youngest plants leveled similarly) for the experiments. Inflorescences were selected randomly but flower heads were selected purposively. The idea behind Maximum variation sampling is to look at a subject from all available angles, thereby achieving a greater understanding (Etikan et al.,2017). Nine trees with each replication for three ages of plants proposed for experiments or three oldest trees, three medium trees, and three youngest trees and three layers were taken for the experiment from each tree $=3 * 9=27$.

\section{Collection and measuring of nectar volume and concentration}

Nectar volume and concentrations were taken and measured from all three layers of the trees and four flower heads were taken from each layer of trees from all ages. Each sample of flowers was representing separate layers of the trees. Nectar volume was measured after being collected by micropipette tips and brought to the laboratory.

Collection of soil sample and measuring its moisture contents

Soil samples were collected from the area of the oldest, medium, and youngest plants of $C$. macrostachyus Hochst. ex Delile and their weight were measured by sensitive balance.

Caging of trees inflorescences for nectar collections after selected based on their ages

Nine trees of $C$. macrostachyus Hochst. ex Delile were selected; three oldest, three medium, and three youngest plants, and then their age of inflorescences was determined based on maximum variation purposive sampling methods, and then their nectar was collected and measured. Nectar was measured from four flower heads of each layer after inflorescences were selected randomly for each layer (upper layer, medium, and bottom layers or lower layers) in the morning and afternoon to evaluate time effects on nectar concentration and volume. Nectar sugar concentration in the nectar produced per flower was measured in the field (as sucrose equivalent) using a hand refractometer (American Optical 10431, Buffalo, NY; range concentration 0-45, BRIX units, at the time of peak nectar secretion in the day, as sucrose equivalent (Das et al., 2014). Sugar concentration and nectar volume were quantified (Veits et al.,2018).

\section{Data compilation and analysis}

Sequences of steps were used: First, all plants in a population were counted, samples were selected and sampled. After sampling, data were inserted into computer Microsoft excel 2010 and imported to R software version 3.44. Multilevel analysis was used to see the interaction between variables affecting nectar volume and concentration of $C$. macrostachyus.ANOVA was used to see the significance of these variables on nectar volume and concentration. 


\section{Result And Discussions}

Associations of nectar volume, humidity of soil, and nectar concentration of $C$. macrostachyus indicated that medium plants taken from the area of soil humidity of $30.4 \%$ had a moderate nectar concentration of $27.2 \%$ and youngest plants taken from the area of the soil humidity of $62.4 \%$ had lower nectar concentration of $16.7 \%$ Oldest plants taken from the area of soil humidity of $27.29 \%$ had highest nectar concentrations $36.5 \%$ this infers effect of soil humidity is significant on nectar concentration $(p=$ $0.000)$. Effects of nectar concentration is significance on nectar volume $(p=0.000)$. Interaction of soil humidity and nectar concentration has no significant $(p>0.05)$ effects on nectar volume when nectar concentration increases, whereas nectar volume decreased. This finding is in line with the finding of (Rutikanga et al., 2016).

An effect of daylight time is significant on concentration of nectar $(p=0.000)$ and effects oftrees layers is significant on concentration of nectar $(p=0.000)$ (Figure 2). Interaction of daylight time and tree layers significantly affect nectar concentration with $p>0.05$. Nectar concentration increased after lunch for the oldest, medium, and youngest age of $C$. macrostachyus. This infers the age of plants and daylight time determined volume and concentrations of nectar. A similar finding reportedthatnectar secretion largely growing trend early in the early hours of the day, peaking toward noontime (Adgaba et al., 2017).

The interaction among relative humidity, daylight time, and nectar volume of crotonindicated that daylight time and relative humidity affected nectar volume as shown below (Figure 3). An effect of relative humidity is significant on nectar volume $(p=0.000)$. An effect of daylight time is not significant on nectar volume $(p>0.05)$ and interaction of relative humidity and daylight time has no significant effects on nectar volume $(p>0.05)$. Nectar volume was higher before lunch than in after lunch for all three-age categories at the time where relative humidity was higher. This speculation in the morning more humidity is found in an air that increases nectar volume. Nectar volume was lower after lunch at the time relative humidity decreasedthat might be due to reduction of relative humidity because of increment of evaporation in the afternoon than in the morning since temperature increases.

Relative humidity has significant effects on nectar concentrations $(p=0.000)$ and daylight time has significant effect on nectar concentration with $(p=0.000)$ (Figure 4). Nectar concentration was lower at the time relative humidity was higher in the morning, but in the afternoon nectar, concentration was higher at the time relative humidity was lower which means relative humidity and nectar concentrations are inversely comparative to each other. Interaction of daylight time and relative humidity has significant effects on nectar concentration with $p=0.0001$ and this result is parallel to reports on Callistemon citrinus L. (Kasim, 2019).

Figure 5: Below shows interactions of temperature, daylight time, and nectar concentrations of Croton macrostachyus. Temperature has significant effects on nectar concentration with $(p=0.000)$ and daylight time significantly affect nectar concentration with $(p=0.0098631)$ and their interactions also significantly affect nectar concentrations with $(p=0.0008304)$. After lunch nectar concentration increased this implies daylight time has a significant effect on nectar concentrations due to increment in 
temperature after lunch. Nectar concentrationwas lower before lunch than after lunch. Similarly, it was reported that there was an increasing concentration as temperature increases with a corresponding decrease in relative humidity (Adriana de Fidalgo and Astrid deep Kleinert, 201, Adjaloo, 2015 ).

Figure 6: Below shows interactions of temperature, daylight time, and nectar volume of Croton macrostachyus. Temperature has significant effects on nectar volume $(p=0.0002499)$. Daylight time did not significantly affect nectar volume $(p>0.05)$ and their interaction has also no significant with $(p>$ 0.05). After lunch, nectar volume decreased which means that daylight time affects nectar volume due to higher temperature after lunch that decreased nectar volume. Similarly, reported as nectar volume of Melliferous plants was higher in the morning (Adjaloo, 2015). This implies nectar volume is affected by daylight time for different species also that might be due to temperature increases in the after lunch than in the pre-lunch hours of the day.

Temperature and soil moisture has significant effects on nectar volume $(p=0.00016$ and 0.0000$)$ respectively, and their interactions has also significant effects with $(p=0.0005800)$ (Figure 7). Age and relative humidity have significant effects with $(p=0.000$ and 0.000$)$ respectively and their interaction has significance effects with $(p=0.0003717)$. Time has no significant effects on nectar volume with $(p>$ $0.05)$, but age has significant effects on volume $(p=0.000)$, but their interaction has significant on volume with $p$-value of $(p=0.006993)$. This is in line with the finding demonstrated with defoliation experiments conducted on Impatiens glandulifera that only a fraction of the day's nectar secretion depends on the day's photosynthesis (Cawoy, 2008).

Age, humidification, then daylight time has significant effects with $(p=0.000,0.000$ and 0.0003643$)$ respectively and their interaction has significant effects with $(p=0.0004939)$ (Figure 8$)$. Interactions of age and layers of trees have significant effects with $(p=0.007700)$. Interaction of daylight time and humidification, has significant effects with $(p=0.0002)$. Interaction of age and daylight time has significant effects with $(p=0.000)$. This deduces age and daylight time has significant effects on nectar volume and youngest age produced more nectar volume than medium and oldest age that might be due to bleeding of water from several tissues of youngest than others. Daylight time, relative humidity and layers of trees significantly affect nectar concentration with $(p=0.0003643,0.000$ and 0.000$)$ respectively and their interactions has significant effects on nectar concentration $(p=0.0024012)$. Interaction of temperature, age, layers, and daylight time has significant effects with $(p=0.041298)$. The highest nectar volume had the lowest sugar concentration and this finding is in line with the finding of (Rutikanga et al., 2016).

\section{Conclusions}

Volume and concentration of nectar of intermediate and eldest age of C. macrostachyus was affected by age of plants, daylight time, relative humidity, temperature, layers of trees, and soil moisture, but for youngest plants nectar volume was not affected by relative humidity and nectar concentration was not affected by temperature. Youngest, Medium, and oldest ages had nectar concentrations of $9.1 \mathrm{w} / \mathrm{w}, 16.7$ 
$\mathrm{w} / \mathrm{w}$, and $36.5 \mathrm{w} / \mathrm{w}$ respectively in the afternoon and the morning $2.7 \mathrm{w} / \mathrm{w}, 5.7 \mathrm{w} / \mathrm{w}$, and $10.1 \mathrm{w} / \mathrm{w}$ respectively. I generalize that upcoming temperature increase possibly will harm the nectar production of plant species, since for Croton also maximum temperature to produce nectar was $30 \mathrm{C} \otimes$ and above this temperature, no nectar production was seen and may have negative effects on honey productions since nectar quality will be lost if climate changes since temperature rises and that can cause a loose of volatile compounds found in nectar those determine the quality of nectar as well honey since for quality honey quality nectar is necessary. For three ages of $C$. macrostachyus lower layers recorded lower nectar concentration and higher nectar volume when compared to the medium and top layers of the trees in the morning. In the afternoon higher nectar concentration and lower nectar volume were recorded in the top layer than the medium and lower layers of the trees.

\section{Declarations}

Ethics approval and consent to participate: Not applicable

Availability of data and materials: The data sets analyzed during the current study are available

Competing interests: The authors declare that they have no competing interests.

Authors' contributions: All authors read and approved the final manuscript for publications

Acknowledgments

First and foremost, I am grateful to acknowledge my advisors Dr. Getachew Sime and Dr. Zufan Bedewi for his/her supervision, critical comments, suggestion, valuable time spent with me in the laboratory and fieldwork, and devoted their time to add essential points to improve the quality of my research paper. It is my privilege to acknowledge Dr. Beyene Dobo and Mosisa Daba for their assistance during laboratory work; I need to acknowledge Dr. Abiot Deddefo who was encouraging me on everything for my success and Dr. Feto Esmo general director of Oromia research institute for his help in teaching me R software that helped me to analysis my data.

Funding: It was funded by Oromia agricultural research institute

\section{References}

1. Adgaba N, Al-Ghamdi A, Tadesse Y, Getachew A, Awad AM, Ansari MJ, Owayss AA, Mohammed SEA, Alqarni AS (2017) Nectar secretion dynamics and honey production potentials of some major honey plants in Saudi Arabia. In Saudi Journal of Biological Sciences (Vol. 24, Issue 1, pp. 180-191). https://doi.org/10.1016/j.sjbs.2016.05.002

2. Adjaloo MK (2015) Nectar production dynamics in two melliferous plant species. Nectar Production Dynamics in Two Melliferous Plant Species, January 
3. Alemayehu G (2018) Ethnobotanical profile of Croton macrostachyus (Euphorbiaceae) in Ethiopia: Review of the literature. Ethnobotanical Profile of Croton Macrostachyus (Euphorbiaceae) in Ethiopia. Review of the Literature, pp 209-222

4. Meresa A, Ashebir A, Gemechu R, W., \& Teka F (2019) Ethno medicinal uses, phytochemistry and antimalarial effect of Croton Ethno medicinal uses, phytochemistry and anti- malarial effect of Croton macrostachyus (Bisana): A review. Ethno Medicinal Uses, Phytochemistry and Anti-Malarial Effect of Croton Ethno Medicinal Uses, Phytochemistry and Anti- Malarial Effect of Croton Macrostachyus ( Bisana ). A Review, March

5. Cawoy VALE, R. I. E (2008) Morphology of Nectaries and Biology of Nectar Production in the Distylous Species Fagopyrum esculentum. Morphology of Nectaries and Biology of Nectar Production in the Distylous Species Fagopyrum Esculentum, Bjo 2007, 675-684. https://doi.org/10.1093/aob/mcn150

6. Das M, Vidal G, Jong DDE, Wien HC, Morse RA (2014) Nectar and pollen production in pumpkin (Cucurbita pepo L.). Nectar and Pollen Production in Pumpkin (Cucurbita Pepo L.), January. https://doi.org/10.1590/S0100-84042006000200008

7. Edge AA (2010) Characteristics of Nectar Production and Standing Crop in Campsis radicans (Bignoniaceae). https://dc.etsu.edu/etd/1694/

8. Etikan I, Musa SA, Alkassim RS (2017) Comparison of Convenience Sampling and Purposive Sampling Comparison of Convenience Sampling and Purposive Sampling. February. https://doi.org/10.11648/j.ajtas.20160501.11

9. Farkas A (2012) Variation in Nectar Volume and Sugar Concentration of Allium ursinum L. ssp. The cientific WorldJOURNAL Variation in Nectar Volume and Sugar Concentration of Allium ursinum L. ssp. ucrainicum in Three Habitats. Variation in Nectar Volume and Sugar Concentration of Allium Ursinum L. Ssp. The Cientific WorldJOURNAL Variation in Nectar Volume and Sugar Concentration of Allium Ursinum L. Ssp. Ucrainicum In, May 2014. https://doi.org/10.1100/2012/138579

10. Jones HG (2015) Stomatal control of photosynthesis and transpiration. Stomatal Control of Photosynthesis and Transpiration, March 1998. https://doi.org/10.1093/jexbot/49.suppl

11. Kasim Roba (2019) International Journal for Research in Agricultural and Food Science ISSN. International Journal for Research in Agricultural Food Science ISSN 2208-2719(11):2208-2719 113.

12. Lu N, Li X, Li L, Zhao Z (2015) Variation of nectar production in relation to plant characteristics in protandrous Aconitum gymnandrum Study species. 8(2), 122-129. https://doi.org/10.1093/jpe/rtv020

13. Obey JK, Ngeiywa MM, Kiprono P, Omar S, Wright A, Von, Kauhanen J, Tikkanen-kaukanen C (2018) Antimalarial Activity of Croton macrostachyus Stem Bark Extracts against Plasmodium berghei In Vivo. Antimalarial Activity of Croton Macrostachyus Stem Bark Extracts against Plasmodium Berghei In Vivo, 2018 
14. Robert K (2007) Original article Botanical sources and sugar concentration of the nectar collected by two stingless bee species in a tropical African rain forest *. Original Article Botanical Sources and Sugar Concentration of the Nectar Collected by Two Stingless Bee Species in a Tropical African Rain Forest *, 38, 110-121

15. Rodríguez-Peña N, Stoner KE, Flores-Ortiz CM, Ayala-Berdón J, Munguía-Rosas MA, Sánchez-Cordero V, Schondube JE (2016) Factors affecting nectar sugar composition in chiropterophilic plants. Revista Mexicana de Biodiversidad 87(2):465-473. https://doi.org/10.1016/j.rmb.2016.03.002

16. Rutikanga A, Tusiime G, Night G, Ocimati W, Blomme G (2016) Variation in nectar volume and sugar content in male flowers of Musa cultivars grown in Rwanda and their non-effect on the numbers of visiting key diurnal insect vectors of banana Xanthomonas wilt. Variation in Nectar Volume and Sugar Content in Male Flowers of Musa Cultivars Grown in Rwanda and Their Non-Effect on the Numbers of Visiting Key Diurnal Insect Vectors of Banana Xanthomonas Wilt, 11(8), 607-623. https://doi.org/10.5897/AJAR2015.10476

17. Stillman PE, Holbrook PK, Baker HGT, Eicher HM (1916) Environmental influences on nectar secretion. environmental influences on nectar secretion, 37

18. Stoner KE, Flores-ortiz CM, Ayala-berdón J, Rodríguez-pe N, Munguía-rosas, M. A., Sánchez-cordero, V., \& Schondube, J. E. (2016). Revista Mexicana de Biodiversidad Factors affecting nectar sugar composition in chiropterophilic plants. Revista Mexicana de Biodiversidad Factors Affecting Nectar Sugar Composition in Chiropterophilic Plants, 87, 465-473. https://doi.org/10.1016/j.rmb.2016.03.002

19. Takkis K, Tscheulin T, Petanidou T (2018) Differential Effects of Climate Warming on the Nectar Secretion of Early- and Late-Flowering Mediterranean Plants. Warming on the Nectar Secretion of Early- and Late-Flowering Mediterranean Plants, 9(June), 1-13. https://doi.org/10.3389/fpls.2018.00874

20. Veits M, Khait I, Obolski U, Zinger E, Boonman A, Goldshtein A, Ben-dor U, Estlein P, Kabat A, Peretz D, Ratzersdorfer I, Krylov S, Chamovitz D, Sapir Y, Yovel Y, Hadany L, Security F (2018) I. Title page. Flowers Respond to Pollinator Sound within Minutes by Increasing Nectar Sugar Concentration

21. Zhang ZJ, Shi L, Zhang JZ, Zhang CY (2004) Photosynthesis and growth responses of Parthenocissus quinquefolia(L.) Planch to soil water availability. Hotosynthesis and Growth Responses of Parthenocissus Quinquefolia (L.). Planch to Soil Water Availability 42(1):87-88

\section{Figures}




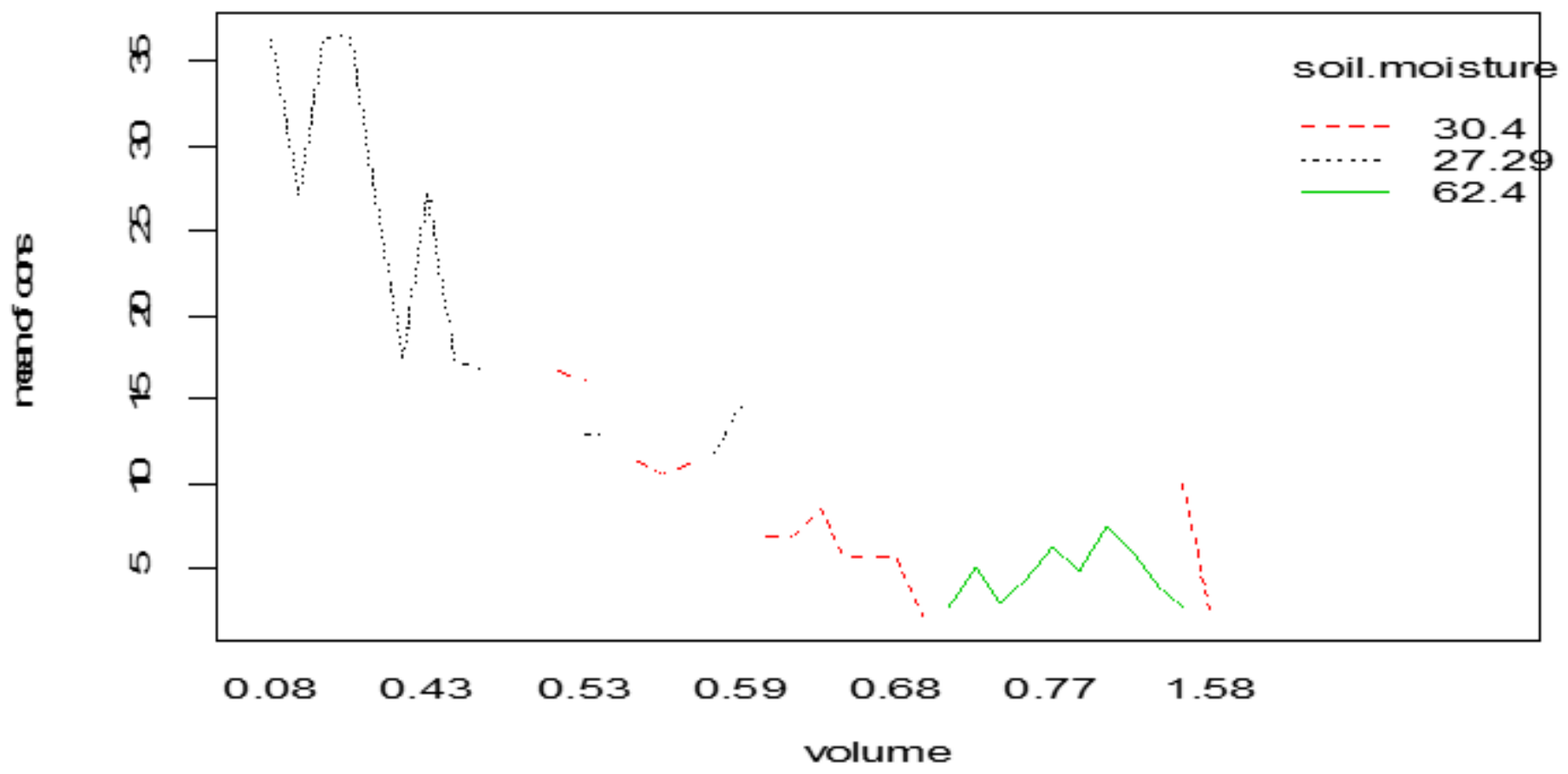

Figure 1

Interaction of nectar volume, wetness of soil, and nectar concentration of C. macrostachyus Hochst.ex Delile.

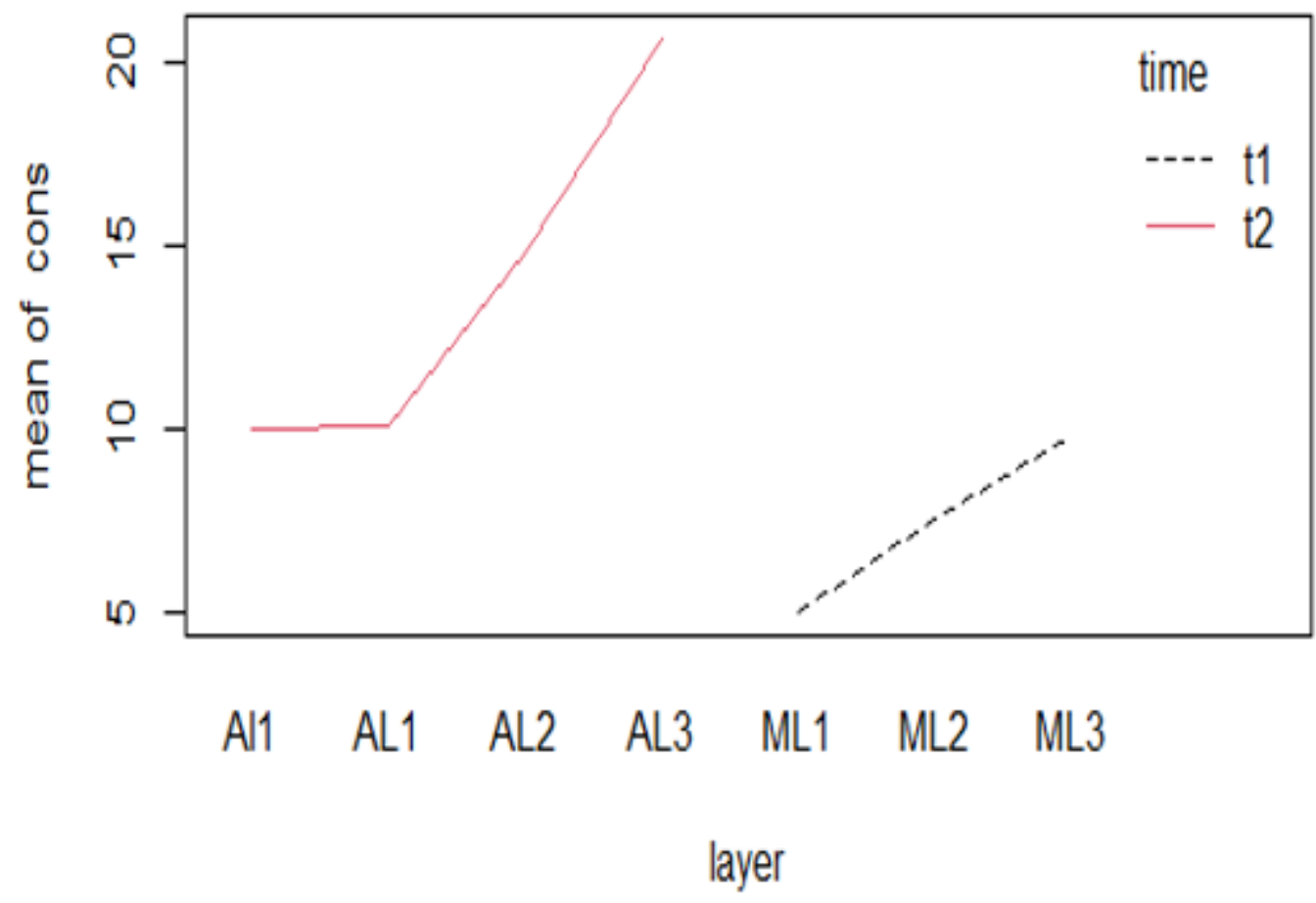

Figure 2

Interaction of trees layers, concentration of nectar of Croton macrostachyus and daylight time 


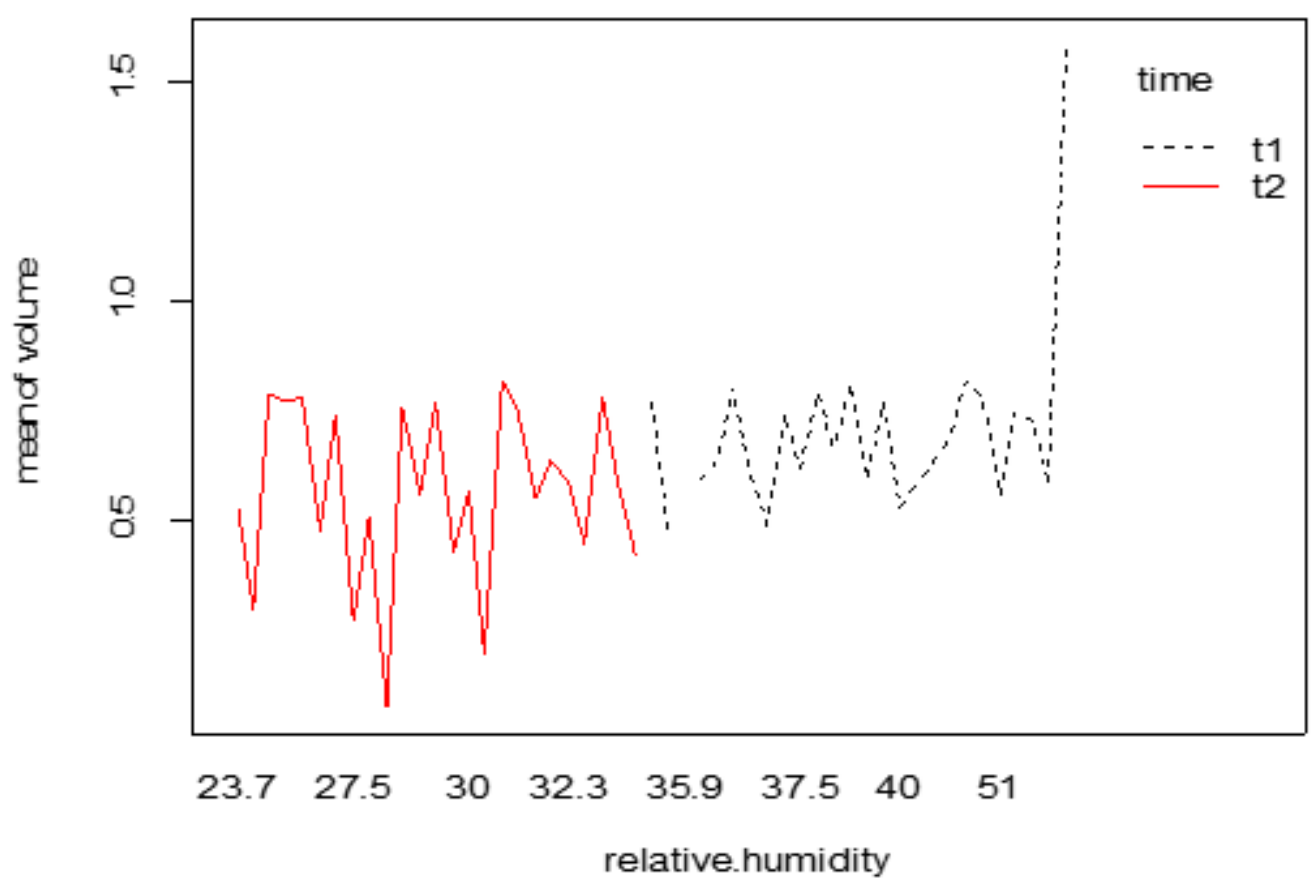

Figure 3

Interaction of relative humidity, daylight time, and nectar volume of C. macrostachyus Hochst.ex Delile

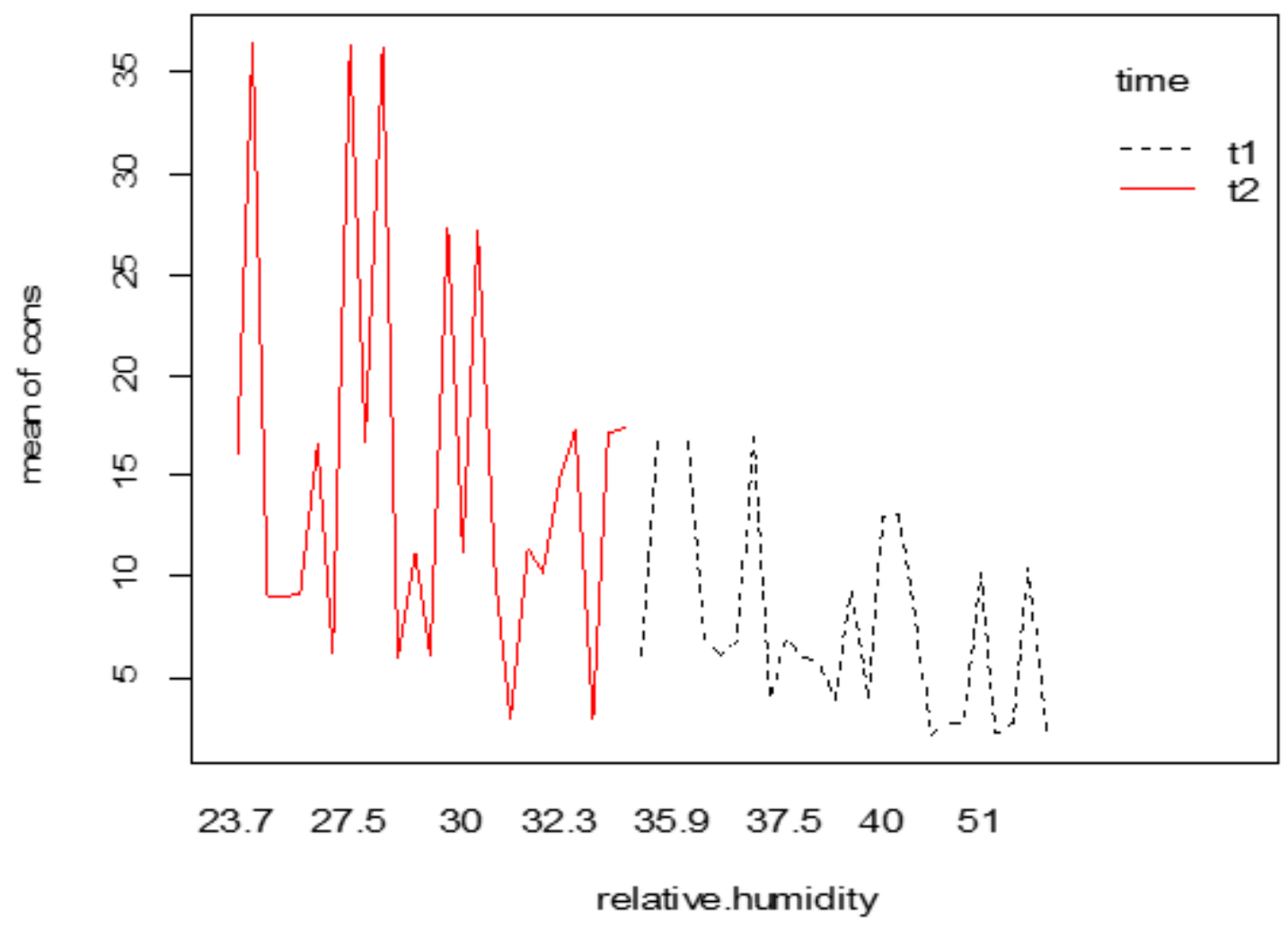

Figure 4 
Interaction of relative humidity, time, and concentration of nectar of Croton macrostachyus

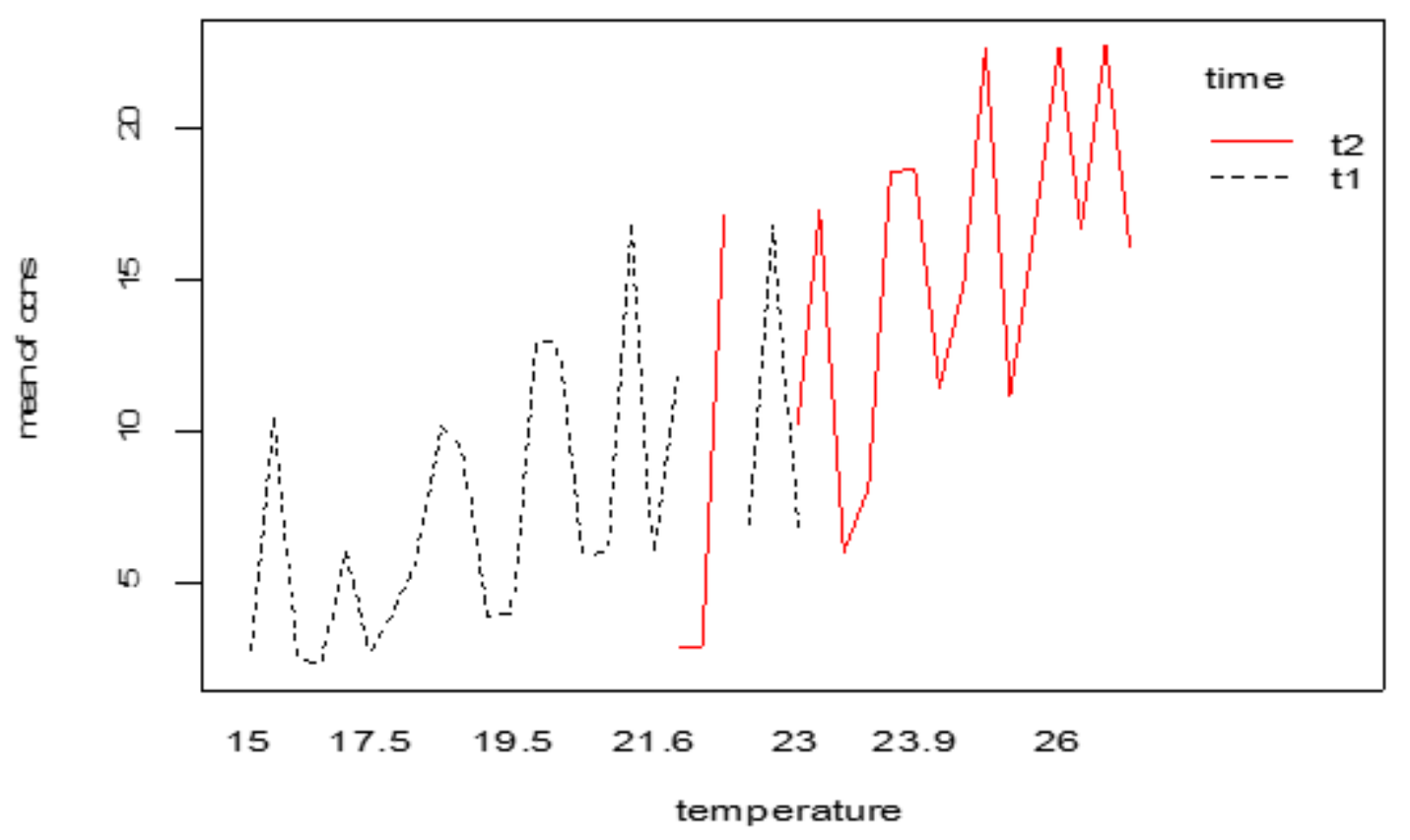

Figure 5

Interaction of temperature, daylight time, and nectar concentration of C. macrostachyus Hochst.ex Delile

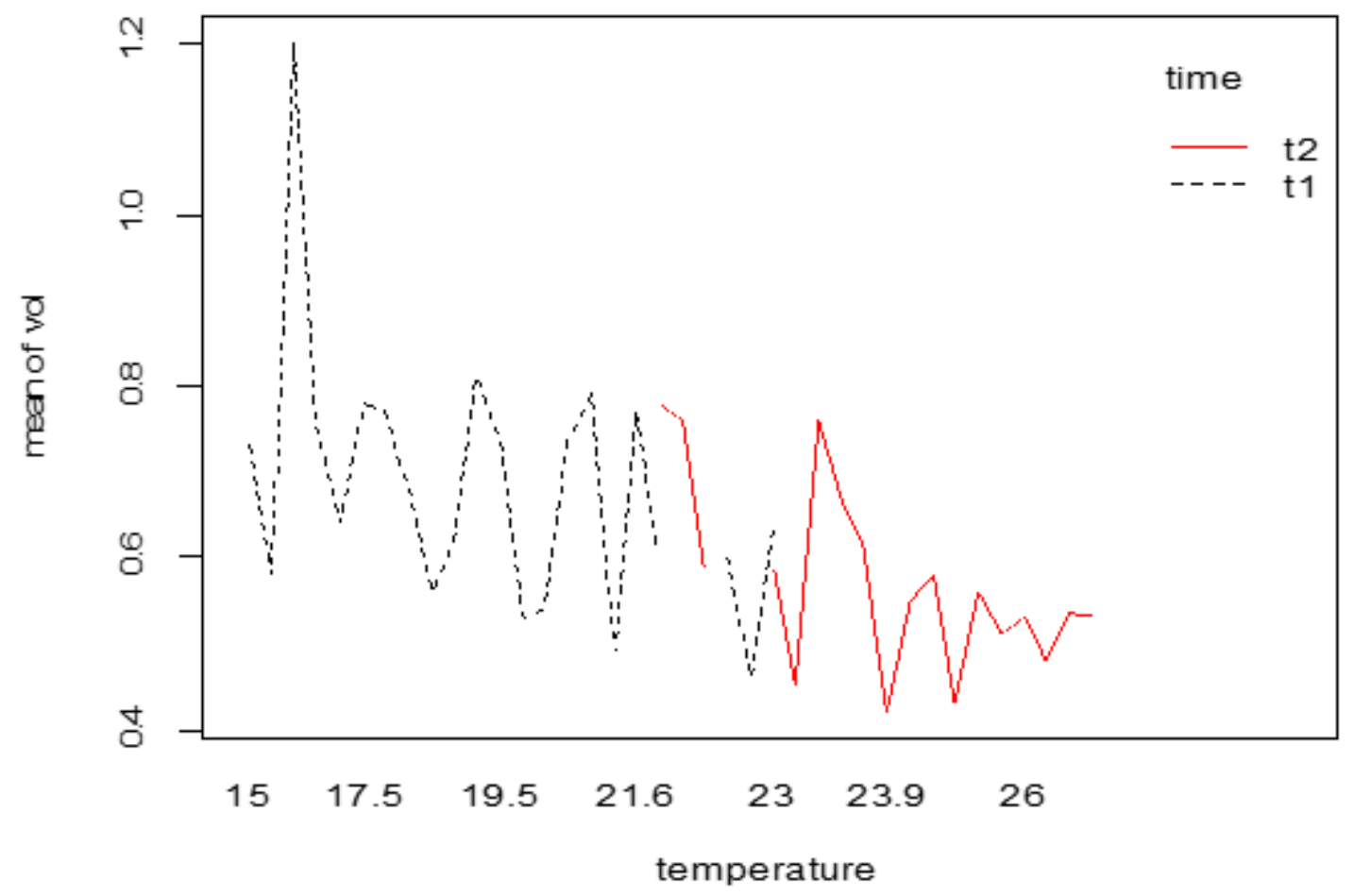

Figure 6

Interaction of temperature, daylight time, and nectar volume of C. macrostachyus Hochst.ex Delile 


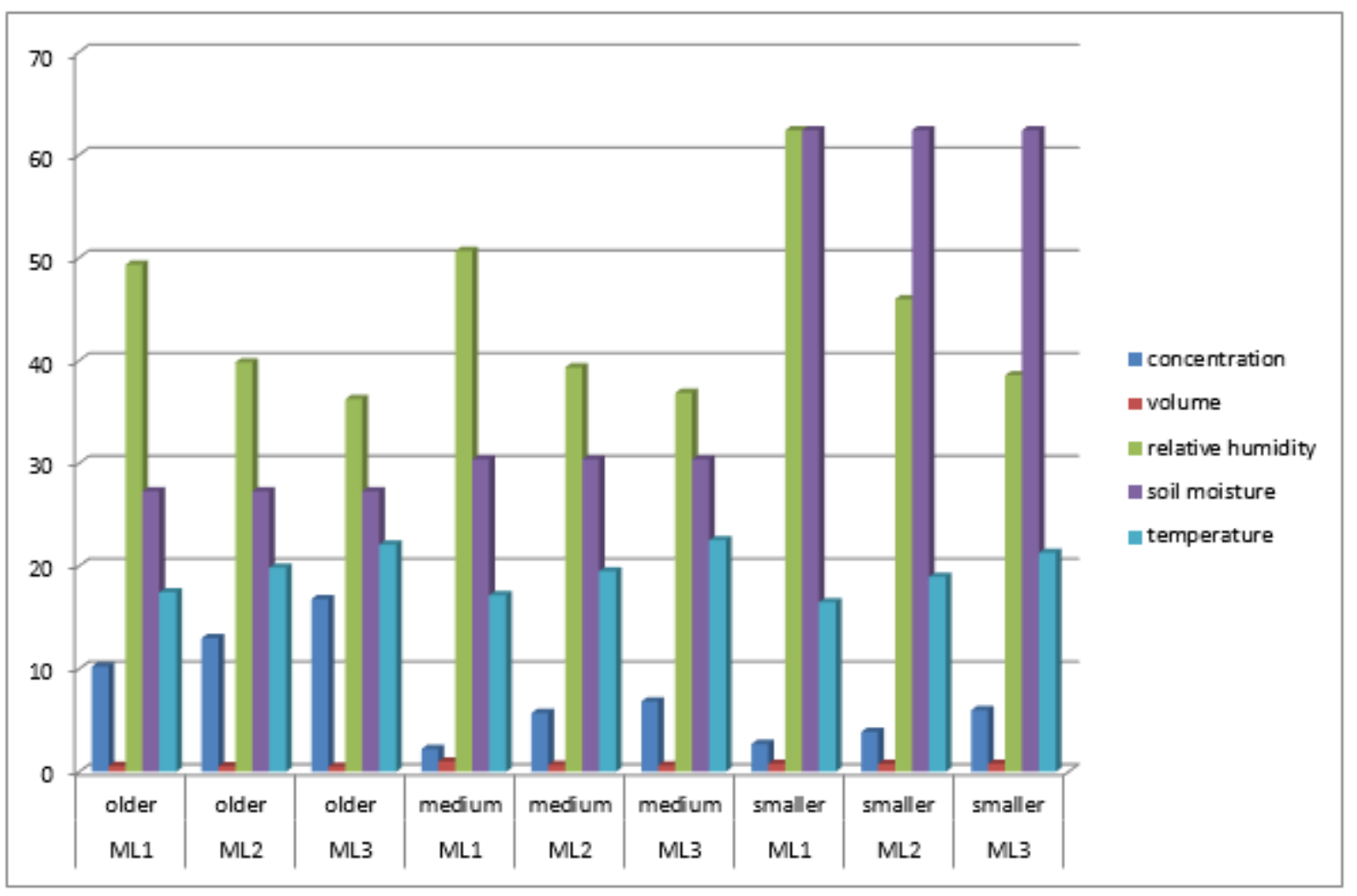

\section{Figure 7}

Interaction of nectar volume and concentration (\%) of three age categories of plants in the morning with temperature, relative humidity, and soil moisture and tree layers

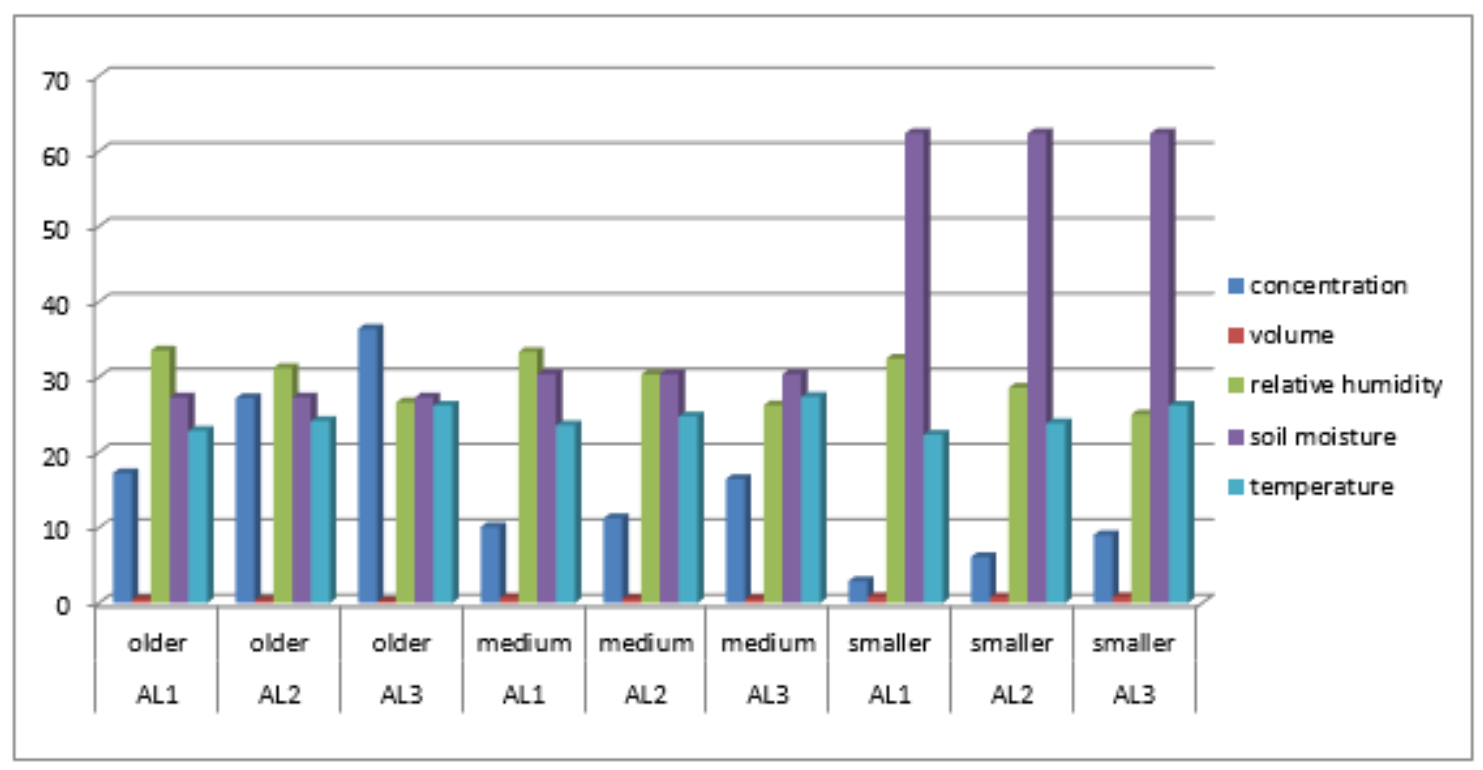

Figure 8

Interaction of nectar volume and concentration (\%) of three plant age categories in the afternoon with soil moisture, temperature, relative humidity, and layers of trees. 